\title{
The evolution of shape in the wing dimorphic cricket, Allonemobius socius
}

\author{
DEREK A. ROFF* \& MICHAEL J . BRADFORD† \\ Department of Biology, McGill University, 1205 Dr Penfield Ave., Montreal, Quebec, Canada, H3A 1B1
}

\begin{abstract}
Many traits which show only two phenotypic morphs are polygenically determined. For such traits the threshold model of quantitative genetics provides a suitable theoretical basis for the estimation of genetic parameters and response to selection. A consequence of this model is that traits correlated to the threshold trait are predicted to change, both in terms of their overall mean value and their morph-specific values. The cricket Allonemobius socius is wing dimorphic with the morphs also showing differences in the shape of the thorax. In this paper we present a quantitative genetic analysis of shape variation in relation to wing morph in A. socius. Overall size, as measured by the first principal component, has a high heritability (0.64 and 0.63 for females and males, respectively), as also does shape, as measured by the first principal component of a size-adjusted principal component analysis (PCA), (0.40, 0.25). However, size is neither phenotypically nor genetically correlated with wing morph, whereas shape is highly correlated, both phenotypically $(0.64,0.49)$ and genetically $(0.80,0.46)$, with wing morph. An analysis of the correlated response of shape to selection on the incidence of macroptery predicts that within populations the two morphs will remain different in shape, but different morphs from separate populations may be very similar in shape.
\end{abstract}

Keywords: dimorphism, genetic correlations, heritability, quantitative genetics, threshold traits.

\section{Introduction}

Environmental variation, both spatial and temporal, is a ubiquitous aspect of the natural world. Such variation can render habitats unsuitable for growth and reproduction, either temporarily or permanently. As a consequence, migration (used in the more general sense of movement between habitats without return) is a common feature of many animal and plant species. In many species of insects there are two distinct wing morphs, one morph bearing fully developed wings (macropterous) and capable of flight, and a second flightless morph with reduced wings (micropterous, brachypterous or apterous; Roff, 1996). The former is a potential migrant, whereas the latter is typically restricted to movement within a habitat and cannot readily move between patches. This dichotomy in migratory potential has been demonstrated in studies where it has been found that newly established habitats are colonized

\footnotetext{
*Correspondence. E-mail: droff@bio1.lan.mcgill.ca

$\dagger$ Present address: Department of Fisheries and Oceans, West Vancouver Laboratory, 4160 Marine Dr, West Vancouver, BC, Canada, V7V 1N6.
}

by winged individuals, with the flightless forms arising as progeny from the initial colonizers (Roff, 1990).

Wing dimorphism is an example of a larger class of dimorphic traits, which include paedomorphosis, cyclomorphosis, morphological dimorphisms involved in protection from predation, dimorphic variation in morphological structures used as weapons in combat (typically between males, but also occurring in hydroids), and dimorphic variation in trophic structures (reviewed in Roff, 1996). Theoretical studies of the evolution of dimorphic traits, including wing dimorphism, have assumed that there are two distinct morphs, each categorized by a particular suite of trait values (e.g. Lively, 1986; Moran, 1992; Roff, 1994a). Empirical studies by Fairbairn and her students have shown this assumption to be too simplistic (Fairbairn, 1986; Fairbairn \& Desranleau, 1987; Fairbairn \& Butler, 1990).

The determination of wing dimorphism, and dimorphic traits in general, can be understood using a threshold model in which it is assumed that there is some underlying, continuously distributed variable (termed the liability), such as hormone titre, and a 
threshold of expression. Individuals with values greater than the threshold develop into one morph, whereas individuals below the threshold develop into the alternate morph. Evidence supporting such a physiological model has been found for cyclomorphosis (Jacobs, 1980), colour morphs in lizards (Hews et al., 1994) and wing dimorphism in insects (Zera \& Tiebel, 1989; Fairbairn \& Yadlowski, 1997). The threshold model also resolves the problem that pedigree analysis frequently shows dimorphic variation to be polygenically determined (Roff, 1996) and, because it is based on continuous underlying variation, the above threshold model permits the use of standard quantitative genetic methods (Falconer, 1989). The syndrome of traits associated with a particular dimorphism can now be viewed as a set of genetically correlated traits, the correlation arising in part at least from the influence of a common physiological mechanism. With this model it becomes apparent that the assumption of a fixed set of trait values associated with each morph cannot be correct (Fairbairn \& Butler, 1990; Roff, 1994b); rather, the associated traits are hypothesized to be linearly related genetically and/or phenotypically (or can be transformed to be so) to the liability, and hence the values of the former traits also vary continuously rather than dichotomously (Fairbairn, 1994).

The above model predicts a genetic correlation between the dimorphic trait (actually the liability of the trait but for simplicity this paper refers to the dichotomous trait) and the associated traits within the syndrome. Significant genetic correlations have been found between wing morph and flight propensity in the cricket Gryllus firmus (Fairbairn \& Roff, 1990), between wing morph and wing muscle histolysis in G. firmus (Fairbairn \& Roff, 1990), and between wing morph and fecundity in the crickets G. firmus (Roff, 1994b) and Allonemobius socius (Roff \& Bradford, 1996). Thus far no one has examined the quantitative genetic basis of the differences between morphological traits associated with wing dimorphism (or any other dimorphism).

In some species there is a marked difference in body size and shape between macropterous and micropterous morphs, the difference typically residing in differences in the construction of the thorax (for examples see Roff, 1986, fig. 1). Fairbairn (1992) examined size and shape differences between morphs and sexes of the waterstrider Aquarius (formally Gerris) remigis and showed that macropters have relatively larger thoraxes which also differ in shape from the micropters. These differences presumably reflect constraints caused by the large size of the flight muscles and possibly the mechanical requirements for muscle attachment and strength to sustain the stresses of flight. If, on average, there are size and/or shape differences between morphs, these differences should, according to the model described above, be genetically correlated with morph frequency and, hence, size and/or shape characteristics of the two morphs will change with selection that increases or decreases the frequency of either morph in the population.

In the present paper the results are reported of an examination of genetic variation in morphology in relation to wing morph in the cricket $A$. socius. This species is wing dimorphic (Mousseau \& Roff, 1989) and the two morphs show distinctly different thorax shapes, the pronotum of the macropterous morph being significantly more trapezoid in shape than the micropterous morph (Alexander \& Thomas, 1959). Previous genetic analyses have shown that wing morph is highly heritable $\left(0.52<h^{2}<0.72\right.$; Mousseau $\&$ Roff, 1989). Because of the genetic variation in wing morph and the clear phenotypic difference in thorax shape between the morphs, A. socius is an ideal species with which to examine the hypothesis that the shape of the two morphs will change as a correlated response to selection on the incidence of macroptery.

\section{Materials and methods}

The source and rearing protocol of the stock used in the present analysis are given in Roff \& Bradford (1996) and only a summary is presented here. Adults were paired randomly to produce 64 full-sib families (total sample size $=1163$ ), which were each split between two cages to permit statistical elimination of effects of common environment. Although estimates of genetic parameters from such a design are potentially inflated by dominance variance (Becker, 1985), space limitations and difficulties with mating prevented us from using the preferred half-sib design. However, with respect to morphological variation, dominance variance has been found to be typically very small and have little effect on the heritability estimate (Mousseau \& Roff, 1987; Crnokrak \& Roff, 1995).

Measurements of four morphological traits-head width (including the eyes), front pronotum width, rear pronotum width, and femur length of the rearmost (jumping) leg-were taken using a computerized digitizer. The analysis of size and shape was carried out following the procedure used by Fairbairn (1992) in her analysis of size and shape variation in the wing dimorphic waterstrider Aquarius 
remigis. First, a general principal components analysis (PCA) was run to extract independent indices of size and shape. The first principal component typically extracts a general size measure, whereas the subsequent principal components are weighted primarily by shape, independent of size (Fairbairn, 1992). Changes in shape resulting from allometric vs. isometric changes were separated using a doubly centred PCA based on log-transformed measurements (Somers, 1989). The scores obtained from this analysis are independent of isometric size variation, and will be referred to as 'size-adjusted PCA'. To permit comparison between analyses, logtransformed data were used throughout [where applicable the analyses, including genetic analyses, were run using the raw data: there was no important ( $<10$ per cent) difference between the two].

Heritabilities of the morphological traits and the PCA scores were estimated using a nested analysis of variance to take into account possible cage effects; when cage effects were not significant a one-way analysis of the combined data was used. The heritability of wing morph was estimated assuming a threshold model: the data were scored as 0 (micropterous) or 1 (macropterous) and the intraclass correlation estimated by ANOVA and then the heritability on the underlying scale estimated from the proportion of each morph in the population (for formulae see Mousseau \& Roff, 1989). Because traits differ between the sexes, estimates were made separately for males and females. Standard errors of the heritabilities were estimated, both from the ANOVA output (Becker, 1985) and using the jackknife (Simons \& Roff, 1994).

The genetic correlations between wing morph and morphological components were estimated using wing morph scored as 0 or 1 , a procedure that has been shown to estimate correctly the genetic correlation between a threshold trait and a continuously distributed trait (Mercer \& Hill, 1984). Estimates and their associated standard errors were computed from the ANOVA using the jack-knife procedure (Roff \& Preziosi, 1994).

\section{Results}

\section{Comparison of phenotypic variation between wing morphs}

Females are significantly larger than males for all four traits but a more complex pattern is found with respect to variation between wing morphs within sexes (Table 1). Macropterous individuals have larger femurs and wider rear pronotums than micropterous individuals but the former have narrower front pronotums than the latter. Head width shows no consistent pattern, macropterous females having smaller heads than micropterous females but the reverse being true for males

Table 1 Mean values (mm) of morphological traits according to sex and wing morph in Allonemobius socius

\begin{tabular}{llllll}
\hline & \multicolumn{2}{c}{ Macropterous crickets } & & \multicolumn{2}{c}{ Micropterous crickets } \\
\cline { 2 - 3 } \cline { 5 - 6 } Trait & Females $\left(201^{*}\right)$ & Males (62) & & Females (474) & Males (426) \\
\hline Head width & $0.265(0.001 \dagger)$ & $0.255(0.001)$ & & $0.268(0.0005)$ & $0.234(0.0005)$ \\
Front pronotum & $0.274(0.005)$ & $0.258(0.002)$ & & $0.280(0.0005)$ & $0.260(0.001)$ \\
Rear pronotum & $0.341(0.001)$ & $0.323(0.002)$ & & $0.318(0.0005)$ & $0.298(0.001)$ \\
Femur length & $0.739(0.001)$ & $0.697(0.005)$ & & $0.728(0.001)$ & $0.677(0.001)$ \\
\hline
\end{tabular}

\begin{tabular}{lccc}
\hline & \multicolumn{3}{c}{ Analysis of variance } \\
\cline { 2 - 4 } Trait & Wing morph & Sex & Interaction \\
\hline Head width & $0.381 \ddagger$ & $<0.0001$ & 0.036 \\
Front pronotum & 0.001 & $<0.0001$ & 0.273 \\
Rear pronotum & $<0.0001$ & $<0.0001$ & 0.503 \\
Femur length & $<0.0001$ & $<0.0001$ & 0.180 \\
\hline
\end{tabular}

*Sample size. Because some of the preserved individuals lacked hindlegs and occasionally heads, the sample size for these two traits is slightly smaller in some cases.

$\dagger$ SE.

$\ddagger$ Probability. 
(Table 1). All pairwise correlations between traits are positive, high and statistically significant both before and after partialling out the effects of sex and wing morph (Table 2).

The first principal component accounts for 81.84 per cent of the variation and each trait contributes approximately equally, supporting the hypothesis that this component is a general size component (Table 3 ). In contrast, the second principal component divides the animal into 'front' and 'rear' components, head width and front pronotum being negatively weighted and the rear pronotum and femur being positively weighted (Table 3 ). There is visually a clear separation along the PC1 axis between micropterous males and females but not along the PC2 axis; macropterous males and females appear to differ little along either axis (Fig. 1). For the PC1 scores there are significant differences attributable to $\operatorname{sex}\left(F_{1,1078}=178, P<0.0001\right)$ and wing morph $\left(F_{1,1078}=16, P<0.0001\right)$ but no significant interaction $\left(F_{1,1078}=3.2, P=0.075\right)$. For the second principal component (PC2) scores only wing morph contributes significantly to the variation (wing morph: $F_{1,1078}=548, \quad P<0.0001 ; \quad$ sex: $F_{1,1078}=1.7, \quad P=0.093 ;$ interaction: $F_{1,1078}=0.26$,

Table 2 Correlations between morphological traits in Allonemobius socius. Values in upper triangle are uncorrected for sex or wing morph, values in lower triangle are partial correlations with sex and wing morph held constant. All correlations are significant with or without Bonferroni correction

\begin{tabular}{lcccc}
\hline & $\begin{array}{c}\text { Head } \\
\text { width }\end{array}$ & $\begin{array}{c}\text { Front } \\
\text { pronotum }\end{array}$ & $\begin{array}{c}\text { Rear } \\
\text { pronotum }\end{array}$ & $\begin{array}{c}\text { Femur } \\
\text { length }\end{array}$ \\
\hline Head width & & 0.835 & 0.723 & 0.788 \\
Front pronotum & 0.797 & & 0.669 & 0.741 \\
Rear pronotum & 0.758 & 0.708 & & 0.779 \\
Femur length & 0.745 & 0.688 & 0.740 & \\
\hline
\end{tabular}

$P=0.61)$. Removal of the insignificant interaction term results in an additive model in which both wing morph and sex are significant (wing morph: $F_{1,1079}=691, P<0.0001$; sex: $\left.F_{1,1079}=7.1, P=0.008\right)$.

The first principal component from the size-adjusted PCA resembles that of PC2 from the previous analysis in weighting front and rear components in opposite directions (Table 3). The size-adjusted PC1 (SA-PC1) accounts for 48.06 per cent of the variance, which is very similar to that of PC2 from the unadjusted analysis when the first principal component is omitted $(100 \times 9.15 / 18.12=50.5$ per cent $)$, indicating that $\mathrm{PC} 1$ primarily measures isometric variation in size. Visually there is a clear separation of sex and wing morph along both PC axes, with wing morphs separating most along the first principal component axis (Fig. 1). For neither SA-PC1 nor SA-PC2 is the interaction term (wing $\times$ sex) significant but in both cases sex and wing morph are significant (SA-PC1: wing morph, $F_{1,1079}=573$, $P<0.0001$; sex, $F_{1,1079}=6.2, P=0.013$; SA-PC2: wing morph, $F_{1,1079}=133.9, P<0.0001$; sex, $F_{1,1079}=11.3$, $P=0.001)$.

\section{Genetic analysis}

The heritabilities of the directly measured traits range from 0.41 to 0.68 (Table 4), which is in accord with the general finding on heritabilities of morphological traits (Mousseau \& Roff, 1987). The standard errors estimated from the jack-knife are larger than those estimated from the analysis of variance: given that the nested ANOVA indicated all family effects significant, it seems likely that the true standard errors lie between the two estimates of the standard error. The interpretation of the results does not depend upon which estimates of SE are used. PC1 has a high heritability in both sexes (0.64, 0.63 for females and males, respectively). As expected from the previously described similarity

Table 3 Results of principal components analysis (PCA). Morphological traits were $\log$ transformed

\begin{tabular}{|c|c|c|c|c|}
\hline \multirow[b]{2}{*}{ Trait } & \multicolumn{2}{|c|}{ General PCA } & \multicolumn{2}{|c|}{ Size-adjusted PCA } \\
\hline & PC1 & $\mathrm{PC} 2$ & SA-PC1 & SA-PC2 \\
\hline Head width & -0.928 & -0.208 & -0.679 & -0.085 \\
\hline Front pronotum & -0.899 & -0.352 & -0.793 & 0.016 \\
\hline Rear pronotum & -0.875 & 0.417 & 0.737 & -0.676 \\
\hline Femur length & -0.915 & 0.158 & 0.539 & 0.840 \\
\hline Eigenvalues & 3.27 & 0.37 & 1.92 & 1.17 \\
\hline Per cent variance explained & 81.84 & 9.15 & 48.06 & 29.23 \\
\hline
\end{tabular}


between PC2 and SA-PC1, the heritabilities of these two compound trait measures are very similar (for females, 0.45 vs. 0.40 ; for males, 0.22 vs. 0.25 ): heritabilities of the doublets PC3 and SA-PC2, and PC4 and SA-PC3 are also very similar (Table 4).

Genetic correlations between the measured traits and wing morph are variable, and that between PC1, the size component, and wing morph is not significant for either sex (Table 5). However, there is a large and highly significant genetic correlation between SA-PC1, the shape component, and wing morph (0.80 for females, 0.46 for males, Table 5).
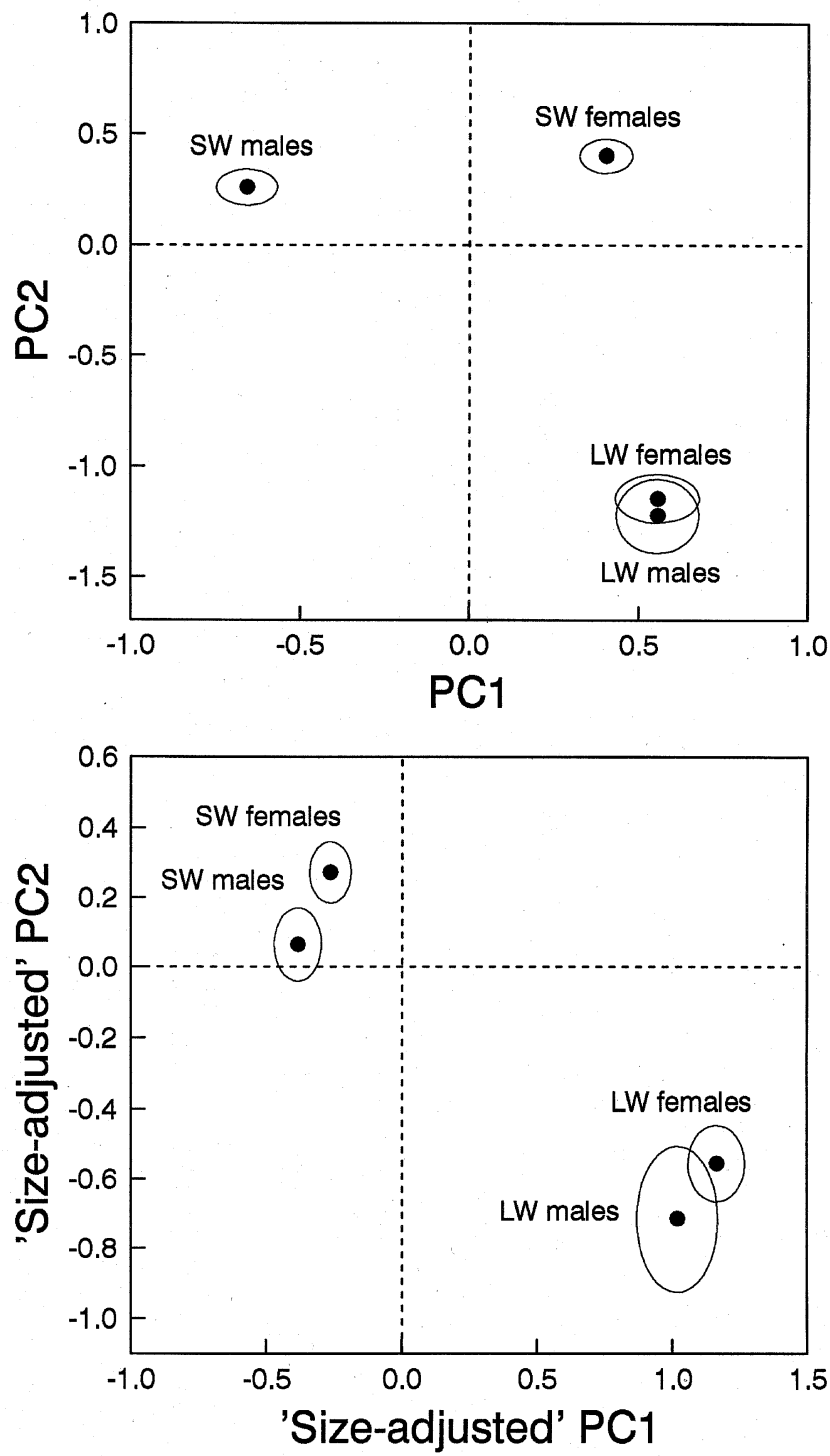

Fig. 1 Mean scores on the first two principal components of a general PCA and a size-adjusted PCA. The ellipses show \pm 2 SE. SW, micropterous; LW, macropterous Allonemobius socius.
Table 4 Heritability estimates $\left(h^{2}\right)$ for trait values (log transformed) and principal component scores ( $\mathrm{SA}=$ sizeadjusted). Standard errors estimated using ANOvA ( $\left.\mathrm{SE}_{\mathrm{A}}\right)$ and jack-knife $\left(\mathrm{SE}_{\mathrm{J}}\right)$. In all cases nested ANOVA indicated a significant 'family' effect

\begin{tabular}{lccccccc}
\hline & \multicolumn{3}{c}{ Females } & & \multicolumn{3}{c}{ Males } \\
\cline { 2 - 3 } \cline { 8 - 9 } Trait & $h^{2}$ & $\mathrm{SE}_{\mathrm{A}}$ & $\mathrm{SE}_{\mathrm{J}}$ & & $h^{2}$ & $\mathrm{SE}_{\mathrm{A}}$ & $\mathrm{SE}_{\mathrm{J}}$ \\
\hline Wing morph & 0.49 & 0.12 & 0.11 & & 0.68 & 0.21 & 0.29 \\
Head width & 0.54 & 0.11 & 0.21 & & 0.68 & 0.13 & 0.27 \\
Front pronotum & 0.47 & 0.11 & 0.17 & & 0.53 & 0.12 & 0.23 \\
Rear pronotum & 0.50 & 0.11 & 0.17 & & 0.57 & 0.12 & 0.22 \\
Femur length & 0.64 & 0.11 & 0.21 & & 0.41 & 0.12 & 0.20 \\
PC1 & 0.64 & 0.11 & 0.25 & & 0.63 & 0.13 & 0.29 \\
PC2 & 0.45 & 0.09 & 0.11 & & 0.22 & 0.11 & 0.11 \\
PC3 & 0.37 & 0.08 & 0.09 & & 0.20 & 0.11 & 0.16 \\
PC4 & 0.22 & 0.09 & 0.07 & & 0.34 & 0.12 & 0.10 \\
SA-PC1 & 0.40 & 0.11 & 0.13 & & 0.25 & 0.12 & 0.16 \\
SA-PC2 & 0.37 & 0.08 & 0.07 & & 0.18 & 0.11 & 0.14 \\
SA-PC3 & 0.20 & 0.09 & 0.07 & & 0.28 & 0.12 & 0.10 \\
\hline
\end{tabular}

Table 5 Phenotypic $\left(r_{\mathrm{P}}\right)$ and genetic $\left(r_{\mathrm{A}}\right)$ correlations between wing morph and other morphological traits of Allonemobius socius. Figures in bold indicate values in which the 95 per cent confidence interval does not include zero (estimate $-2 \mathrm{SE}>0$ )

\begin{tabular}{lrrrr}
\hline Trait & \multicolumn{1}{c}{$r_{\mathrm{P}}$} & $\mathrm{SE}$ & \multicolumn{1}{c}{$r_{\mathrm{A}}$} & $\mathrm{SE}$ \\
\hline Females & & & & \\
Head width & -0.11 & 0.06 & 0.08 & 0.20 \\
Front pronotum & $-\mathbf{0 . 1 6}$ & 0.06 & 0.07 & 0.20 \\
Rear pronotum & $\mathbf{0 . 4 8}$ & 0.03 & $\mathbf{0 . 6 1}$ & 0.11 \\
Femur length & $\mathbf{0 . 1 2}$ & 0.05 & $\mathbf{0 . 3 4}$ & 0.14 \\
PC1 & -0.09 & 0.05 & -0.24 & 0.16 \\
PC2 & $\mathbf{0 . 6 7}$ & 0.03 & $\mathbf{0 . 8 0}$ & 0.09 \\
PC3 & $\mathbf{- 0 . 2 7}$ & 0.05 & -0.10 & 0.23 \\
PC4 & -0.06 & 0.05 & -0.15 & 0.23 \\
SA-PC1 & $\mathbf{0 . 6 4}$ & 0.03 & $\mathbf{0 . 8 0}$ & 0.08 \\
SA-PC2 & $-\mathbf{0 . 4 0}$ & 0.05 & -0.26 & 0.21 \\
SA-PC3 & -0.04 & 0.05 & -0.14 & 0.24 \\
Males & & & & \\
Head width & 0.03 & 0.05 & 0.25 & 0.21 \\
Front pronotum & -0.05 & 0.05 & 0.12 & 0.20 \\
Rear pronotum & $\mathbf{0 . 4 1}$ & 0.05 & $\mathbf{0 . 4 8}$ & 0.14 \\
Femur length & $\mathbf{0 . 1 4}$ & 0.04 & 0.33 & 0.17 \\
PC1 & $-\mathbf{0 . 1 5}$ & 0.04 & -0.32 & 0.18 \\
PC2 & $\mathbf{0 . 5 4}$ & 0.04 & $\mathbf{0 . 4 7}$ & 0.18 \\
PC3 & $\mathbf{0 . 1 5}$ & 0.06 & -0.15 & 0.27 \\
PC4 & 0.04 & 0.05 & 0.25 & 0.29 \\
SA-PC1 & $\mathbf{0 . 4 9}$ & 0.04 & $\mathbf{0 . 4 6}$ & 0.19 \\
SA-PC2 & $-\mathbf{0 . 2 4}$ & 0.07 & -0.26 & 0.28 \\
SA-PC3 & 0.02 & 0.05 & 0.10 & 0.26 \\
\hline & & & &
\end{tabular}

(C) The Genetical Society of Great Britain, Heredity, 80, 446-455. 
Similar genetic correlations are found for PC2 (0.80 for females, 0.47 for males, Table 5). Although the phenotypic correlation between SA-PC2 and wing morph is significant the standard errors on the estimates of the genetic correlations are very large and hence no firm conclusion can be drawn with respect to this principal component.

\section{Analysis of family mean values}

The above analysis is based on the assumption of a continuously distributed underlying trait: if this assumption is correct then the mean family value of the shape parameter SA-PC1 within a wing morph should be correlated with the proportion of macrop- terous individuals in the family, which is itself an estimate of the mean family value of the underlying trait. Because it shows the greatest range, the best estimator of the latter is the proportion of macropterous females in the family (30 per cent of females were macropterous whereas only 13 per cent of males were macropterous. In the latter case sampling variation can be very large, and hence we used this value after arcsine-square-root transformation (Roff, 1994b). Only the micropterous morph was analysed because the number of macropterous individuals within families was frequently less than 10 and hence did not give a reliable estimate of the family mean value. For both females and males there is a highly significant correlation (Fig. 2: note
Fig. 2 Regression of the family mean size-adjusted first principle component (SA-PC1) of micropterous females (above) or males (below) on proportion macropterous females in the family of Allonemobius socius (arcsine-square root transformed). For females a logarithmic transformation $[\log (X+2)$, where $X$ is the shape parameter, SA-PC1] was used to eliminate heteroscedascity: $r=0.436$, $n=63, P<0.0001$. For males, $r=0.348, n=63, P=0.005$. Solid lines show fitted regression lines, dashed line shows the predicted value based on the correlated response to selection (see Discussion for equation and details).
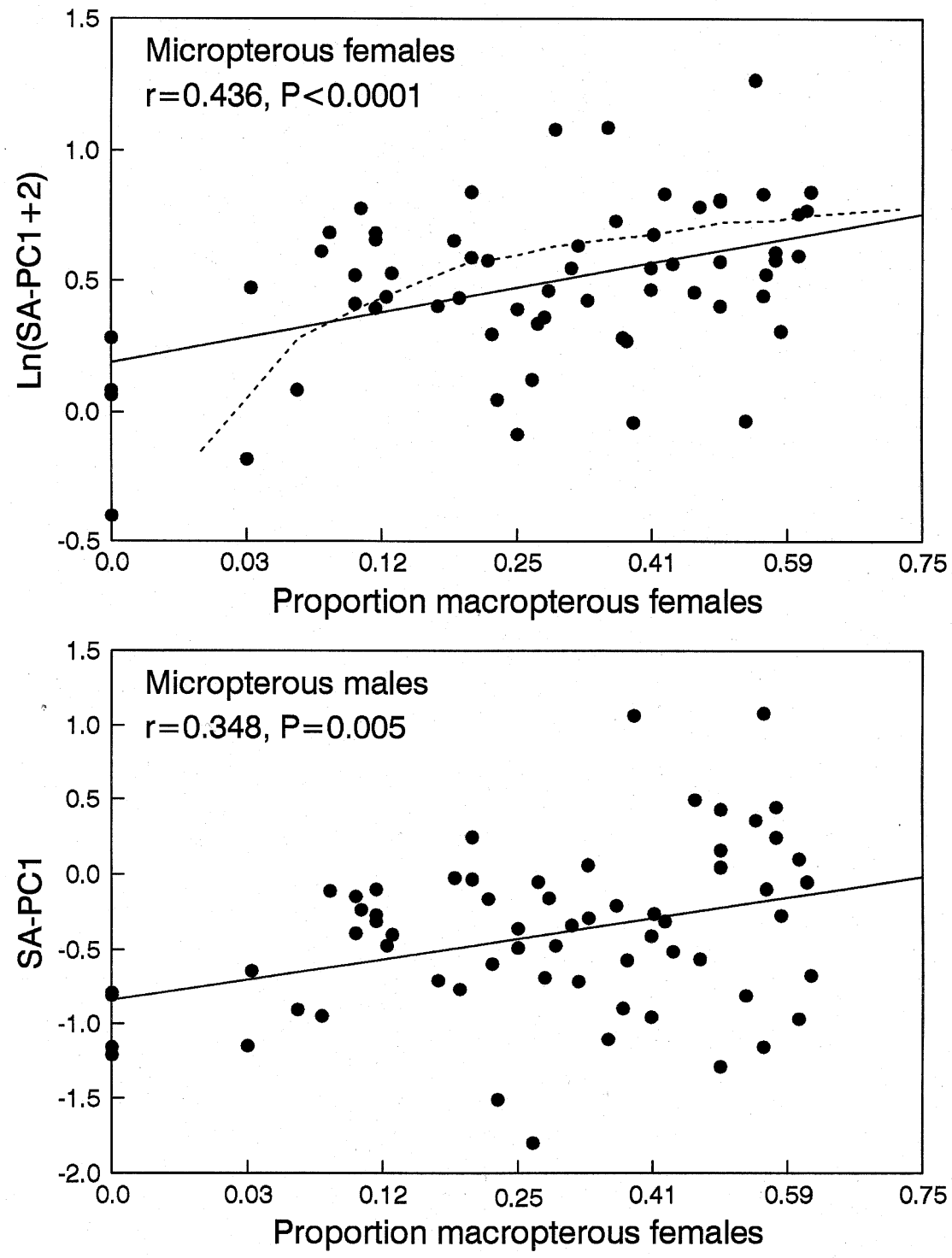


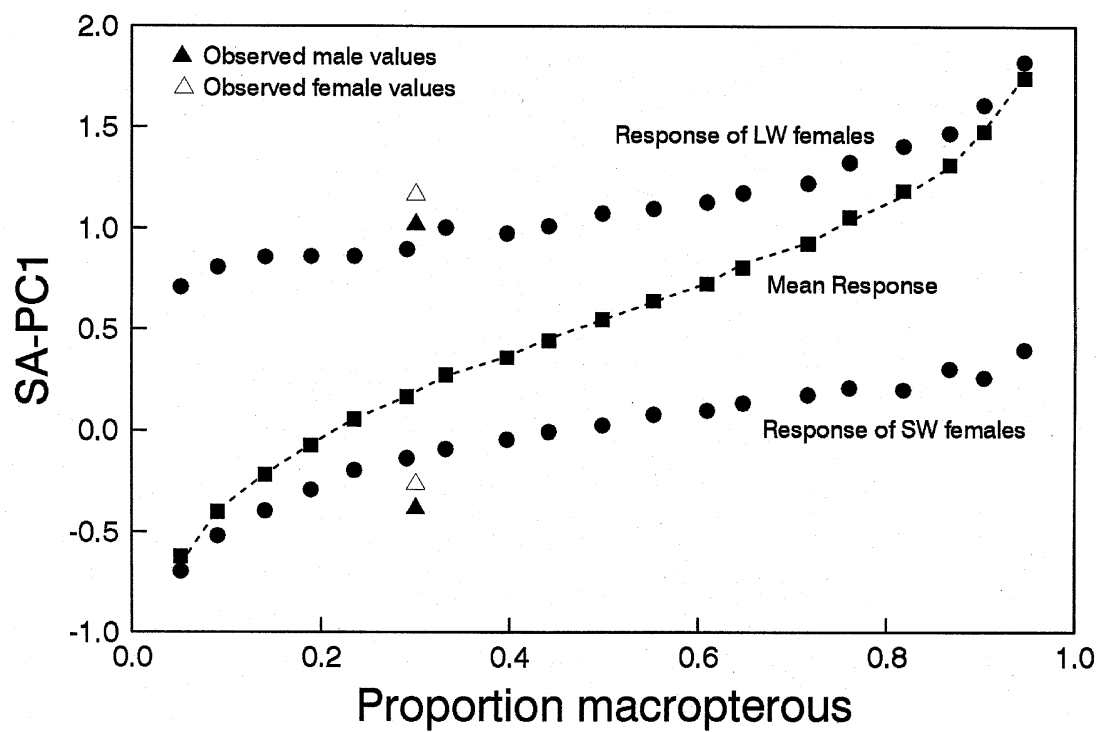

Fig. 3 Predicted correlated change in shape (SA-PC1) of macropterous (LW) and micropterous (SW) female Allonemobius socius in response to selection on proportion macroptery. The solid squares show the mean shape values determined by the simulation, and the dotted line that predicted using the correlated response equation. Dots show mean morph-specific shape values, and triangles indicate the scores in the experimental (initial) population. that a logarithmic transformation was necessary in the case of the female data to eliminate heteroscedascity), supporting the assumption of continuous variation. Thus a micropterous individual that comes from a family consisting mainly of macropterous individuals will be more 'macropterous-like' in body shape than a micropterous individual from a family with a lower proportion of macroptery.

\section{Discussion}

In the waterstrider $A$. remigis wing morphs differ phenotypically in both overall size and shape (Fairbairn, 1992). In contrast, in $A$. socius overall size, as indexed by $\mathrm{PC} 1$, is different between wing morphs within males but varies little within females (Fig. 1). Overall size (PC1) has a high heritability ( 0.64 for females, 0.63 for males) but is not genetically correlated with wing morph, although the associated standard errors are large (Table 5). Assuming the estimated genetic correlations to be of the right order $(\approx 0.25)$, these data indicate that selection on size will produce a rapid direct response but only a small or no correlated response in the size difference between wing morphs. Similarly, direct selection on wing morph (selection for increased or decreased incidence of macroptery) will lead to a rapid direct response $\left(h^{2} \approx 0.59\right)$ but no large change in overall size.

Shape, as indexed by the first principal component of the size-adjusted PCA (SA-PC1), differs markedly between wing morphs and, to a much lesser extent, between the sexes (Fig. 1). The heritability of SA-PC1 is modest in males (0.25) and reasonably large in females (0.40). Unlike overall size, shape is significantly genetically correlated with wing morph ( 0.80 in females, 0.46 in males; this difference is not statistically significant). Thus selection on wing morph will cause a significant change in the mean shape of the two morphs. The extent of the correlated response can be estimated using the standard formulae (Falconer, 1989):

$R_{\mathrm{M}}=i h_{\mathrm{M}}^{2} \sqrt{V_{\mathrm{M}}}$ and $C R_{\text {shape }}=i r_{\mathrm{A}} h_{\text {shape }} h_{\mathrm{M}} \sqrt{V_{\text {shape }}}$,

where $R_{\mathrm{M}}$ is the direct response of selection on the proportion of macroptery $\left(R_{\mathrm{M}}\right.$ is measured on the underlying scale), $i$ is the intensity of selection, $h_{\mathrm{M}}^{2}$ is the heritability of wing morph, $V_{\mathrm{M}}$ is the phenotypic variance, which by definition equals 1 (Roff, 1994b), $C R_{\text {shape }}$ is the correlated response of the shape parameter (SA-PC1), $r_{\mathrm{A}}$ is the additive genetic correlation between wing morph and shape, $h_{\text {shape }}$ is the square root of the heritability of shape and $V_{\text {shape }}$ is the phenotypic variance of the shape parameter. Rearranging the above to eliminate the intensity of selection gives:

$C R_{\text {shape }}=r_{\mathrm{A}} R_{\mathrm{M}} \frac{h_{\text {shape }}}{h_{\mathrm{M}}} \sqrt{\frac{V_{\text {shape }}}{V_{\mathrm{M}}}}$.

The above equation gives the change in the mean shape parameter: the values within each morph were obtained by the following simulation. The response in liability, $R_{\mathrm{M}}$, was varied such that the proportion of macropterous females in the new population ranged from 0.05 to 0.95 , and for each value of $R_{\mathrm{M}}$ a population of 5000 individuals was constructed with trait values determined using the model (Roff \& Preziosi, 1994; adjusted for scaling effects):

(C) The Genetical Society of Great Britain, Heredity, 80, 446-455. 


$$
\begin{aligned}
X_{\mathrm{i}}= & \mu_{x}+a_{x, i} \sqrt{\frac{1}{2} h_{\mathrm{M}}^{2}}+b_{x, i} \sqrt{1-\frac{1}{2} h_{\mathrm{M}}^{2}}, \\
Y_{i}^{*}= & r_{\mathrm{A}} a_{x, i} \sqrt{\frac{1}{2} h_{\text {shape }}^{2}}+a_{y, i} \sqrt{\frac{1}{2}\left(1-r_{\mathrm{A}}^{2}\right) h_{\text {shape }}^{2}} \\
& +r_{\mathrm{E}} b_{x, i} \sqrt{1-\frac{1}{2} h_{\text {shape }}^{2}}+b_{y, i} \sqrt{\left(1-\frac{1}{2} h_{\text {shape }}^{2}\right)\left(1-r_{\mathrm{E}}^{2}\right)}, \\
Y_{i}= & Y_{i}^{*} \sqrt{V_{\text {shape }}}+\mu_{y},
\end{aligned}
$$

where $X_{i}$ is the liability for the $i$ th individual. The threshold value is set at 1 and the mean value in the initial population set such that the proportion of macropterous females, $p$, is the same as that observed $(p=0.30)$. The threshold value remains constant but the mean liability, $\mu_{x}$, changes as a result of selection. If individual $i$ exceeds the threshold, then it is designated a macropterous morph, otherwise it is the micropterous morph. $Y_{i}$ is the value of the shape parameter for the $i$ th individual. $a_{x, i}, a_{y, i}, b_{x, i}$ and $b_{y, i}$ are random standard normal values, $\mathrm{N}(0,1), \mu_{y}$ is the mean value of the shape parameter in the population after selection $(=$ value before selection $\left.+C R_{\text {shape }}\right) \cdot r_{\mathrm{E}}$ is the environmental correlation, given by:

$r_{\mathrm{E}}=\frac{r_{\mathrm{P}}-\frac{1}{2} r_{\mathrm{A}} \sqrt{h_{\mathrm{M}}^{2} h_{\text {shape }}^{2}}}{\sqrt{\left(1-\frac{1}{2} h_{\mathrm{M}}^{2}\right)\left(1-\frac{1}{2} h_{\text {shape }}^{2}\right)}}$,

where $r_{\mathrm{P}}$ is the phenotypic correlation. For the purposes of demonstration the predicted changes in females are used, for which the data are the most precise. It is also assumed that males and females do not differ in parameter values. From the estimated values we have $C R_{\text {shape }}=0.8 \sqrt{(0.40 / 0.49)}$
Fig. 4 Distributions of morph-specific shape value for two populations of Allonemobius socius, one in which the proportion, $p$, of macropterous individuals is 0.05 and the other with $p=0.95$. In both cases 5000 individual values were constructed using the formulae described in the text. The upper panel compares the distribution of shape values of micropterous (SW) individuals from the population in which $p=0.95$ with that of macropterous (LW) individuals from a population in which $p=0.05$. The lower panel shows the alternative.
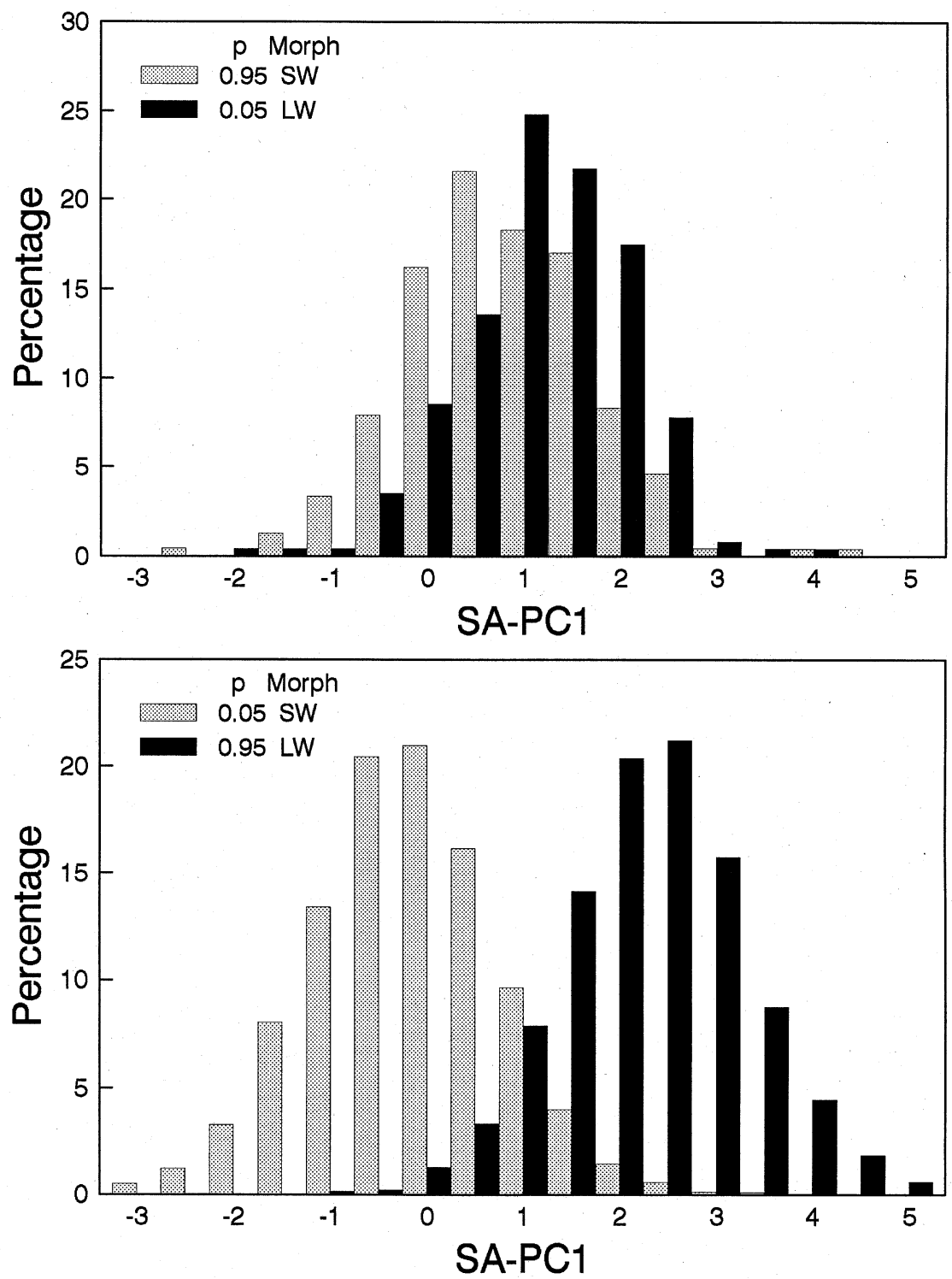

(C) The Genetical Society of Great Britain, Heredity, 80, 446-455. 
$\sqrt{(1.024 / 1)} R_{\mathrm{M}}=0.73 R_{\mathrm{M}}$. Starting from the initial values of the present population (proportion macropterous of 0.30 , mean SA-PC1 in females of 0.163 ) the mean shape values can be estimated when the population has been selected for an increased or decreased proportion of macroptery. This predicted value is also that expected for the relationship between mean family shape value within morphs and proportion of macroptery in the family. The predicted curve for macropterous females is shown in Fig. 2: the curve passes through the mass of the data points and there is a significant correlation between observed and predicted values $(r=0.27$, $n=59, P=0.04$; families in which the proportion macropterous was zero could not be used). The predicted curves covering the range $0.05<p<0.95$ of macropterous and micropterous females is shown in Fig. 3. Both the mean shape value and the morphspecific values show significant nonlinearity (Fig. 3), the morph-specific values changing roughly in parallel. There can be considerable change in shape as a result of selection on macroptery but there is always a clear distinction between morphs within a population. However, the shapes of females of different morphs may closely resemble each other when drawn from different populations; for example, whereas the mean shape of a macropterous female from a population consisting of 5 per cent macropterous females is larger than the mean shape of a micropterous female from a population consisting of 95 per cent macropterous females ( 0.71 vs. 0.28$)$, the overlap is considerable and a large sample size would be required to differentiate them (upper panel, Fig. 4). As expected, the reciprocal combination shows a clear separation (lower panel, Fig. 4).

Although there is no direct evidence for the functional significance of shape variation in A. socius, it seems reasonable to suppose that it is primarily connected to the flight capability of the macropterous morph. There are two ways in which shape may be correlated with flight capability: first, there may be aerodynamical aspects and secondly, there may be constraints caused by the development of the relatively massive dorsal longitudinal flight muscles. Although neither effect can be ruled out, the latter is almost certainly important. Because overall size itself is not correlated with wing morph then: (i) the functional significance of the shape of the thorax has to do more with muscle attachment than simply muscle size; or, alternatively, (ii) muscle size itself is important and increasing the entire body size to accommodate the flight muscles has a lower fitness value than increasing only the thoracic size, which may require a greater enlargement of the rear half than the front. Detailed anatomical studies may resolve this question.

\section{Acknowledgements}

We thank Nathalie Roy and Jackie Farrell for their assistance in conducting the experiment. Drs D. J. Fairbairn and Grey Stirling are greatly thanked for their suggestions on earlier versions of this paper. Financial support was provided by the Canadian Natural Sciences and Engineering Council to D.A.R., and by NSERC and Max Bell fellowships to M.J.B.

\section{References}

AlEXANDER, R. D. AND THOMAs, E. S. 1959. Systematic and behavioral studies on the crickets of the Nemobius fasciatus group (Orthoptera: Gryllidae: Nemobiinae). Ann. Entomol. Soc. Am., 52, 591-605.

BECKER, w. A. 1985. Manual of Quantitative Genetics. McNaughton and Gunn Inc., Ann Arbor, MI.

CRNOKRAK, P. AND ROFF, D. A. 1995. Dominance variance: associations with selection and fitness. Heredity, 75, $530-540$.

FAIRBAIRN, D. J. 1986. Does alary polymorphism imply dispersal dimorphism in the waterstrider, Gerris remigis? Ecol. Entomol., 11, 355-368.

FAIRBAIRN, D. J. 1992. The origins of allometry: size and shape polymorphism in the common waterstrider, Gerris remigis Say (Heteroptera, Gerridae). Biol. J. Linn. Soc., 45, 167-186.

FAIRBAIRN, D. J. 1994. Wing dimorphism and the migratory syndrome: correlated traits for migratory tendency in wing dimorphic insects. Res. Pop. Ecol., 36, 157-163.

FAIRBAIRN, D. J. AND BUTLER, T. C. 1990. Correlated traits for migration in the Gerridae (Hemiptera, Heteroptera): A field test. Ecol. Entomol., 15, 131-142.

FAIRBAIRN, D. AND DESRANLEAU, L. 1987. Flight threshold, wing muscle histolysis, and alary polymorphism: correlated traits for dispersal tendency in the Gerridae. Ecol. Entomol., 12, 13-24.

FAIRBAIRN, D. J. AND ROFF, D. A. 1990. Genetic correlations among traits determining migratory tendency in the sand cricket, Gryllus firmus. Evolution, 44, 1787-1795.

FAIRBAIRN, D. J. AND YADLOWSKI, D. E. 1997. Coevolution of traits determining migratory tendency: correlated response of a critical enzyme, juvenile hormone esterase, to selection on wing morphology. J. Evol. Biol., 10, 495-514.

FALCONER, D. S. 1989. Introduction to Quantitative Genetics, 3rd edn. Longman, New York.

HEWS, D. K., KNAPP, R. AND MOORE, M. C. 1994. Early exposure to androgens affects adult expression of alter-

(C) The Genetical Society of Great Britain, Heredity, 80, 446-455. 
native male types in tree lizards. Horm. Behav., 28, 96-115.

JACOBS, J. 1980. Environmental control of cladoceran cyclomorphosis via target-specific growth factors in the animal. In: Kerfoot, W. C. (ed.) Evolution and Ecology of Zooplankton Communities, pp. 429-437. University of New England Press, Hanover, New England.

LIVELy, C. M. 1986. Canalization vs. developmental conversion in a spatially variable environment. Am. Nat., 128, 561-572.

MERCER, J. T. AND HILL, w. G. 1984. Estimation of genetic parameters for skeletal defects in broiler chickens. Heredity, 53, 193-203.

MORAN, N. 1992. The evolutionary maintenance of alternative phenotypes. Am. Nat., 139, 971-989.

MOUSSEAU, T. A. AND ROFF, D. A. 1987. Natural selection and the heritability of fitness components. Heredity, 59, 181-198.

MOUSSEAU, T. A. AND ROFF, D. A. 1989. Geographic variability in the incidence and heritability of wing dimorphism in the striped ground cricket, Allonemobius fasciatus. Heredity, 62, 315-318.

ROFF, D. A. 1986. The evolution of wing dimorphism in insects. Evolution, 40, 1009-1020.

ROFF, D. A. 1990. Understanding the evolution of insect life cycles: the role of genetical analysis. In: Gilbert F. (ed.) Genetics, Evolution and Coordination of Insect Life Cycles, pp. 5-27. Springer-Verlag, New York.

ROFF, D. A. 1994a. Habitat persistence and the evolution of wing dimorphism in insects. Am. Nat., 144, 772-798.

ROFF, D. A. 1994b. Evidence that the magnitude of the trade-off in a dichotomous trait is frequency dependent. Evolution, 48, 1650-1656.

ROFF, D. A. 1996. The evolution of threshold traits in animals. Q. Rev. Biol., 71, 3-35.

ROFF, D. A. AND BRADFORD, M. J. 1996. Quantitative genetics of the trade-off between fecundity and wing dimorphism in the cricket Allonemobius socius. Heredity, 76, 178-185.

ROFF, D. A. AND PREZIOSI, R. 1994. The estimation of the genetic correlation: the use of the jackknife. Heredity, 73, 544-548.

SIMONS, A. AND ROFF, D. A. 1994. The effect of environmental variability on the heritabilities of traits of a field cricket. Evolution, 48, 1637-1649.

SOMERs, K. M. 1989. Allometry, isometry and shape in principal components analysis. Syst. Zool., 38, 169-173.

ZERA, A. J. AND TIEBEL, K. C. 1989. Differences in juvenile hormone esterase activity between presumptive macropterous and brachypterous Gryllus rubens: implications for the hormonal control of wing polymorphism. J. Insect Physiol., 35, 7-17. 